\title{
Atmospheric levels and distribution of Dechlorane Plus in an E-waste dismantling region of East China
}

\author{
Huizhong Sun ${ }^{1,2}$, Yingming $\mathrm{Li}^{1}$, Pu Wang ${ }^{1}$, Shucheng Zheng ${ }^{1,2}$, Julius Matsiko ${ }^{1,2}$, \\ Dou Wang ${ }^{1,2}$, Weiwei Zhang ${ }^{1,2}$, Yanfen Hao ${ }^{1,2}$, Qinghua Zhang ${ }^{1,2^{*}}$ \& Guibin Jiang ${ }^{1,2}$ \\ ${ }^{1}$ State Key Laboratory of Environmental Chemistry and Ecotoxicology, Research Center for Eco-Environmental Sciences, \\ Chinese Academy of Sciences, Beijing 100085, China \\ ${ }^{2}$ University of Chinese Academy of Sciences, Beijing 100049, China
}

Received June 16, 2016; accepted August 3, 2016; published online October 27, 2016

\begin{abstract}
Atmospheric concentrations of Dechlorane Plus (DP) were investigated in Taizhou, an electronic-waste (E-waste) dismantling region in East China. Passive air samplers with polyurethane foam (PUF) disks were deployed every three months during the sampling period of September 2009-August 2010. The total DP (syn- and anti-DP) concentrations in air ranged from not detected to $277 \mathrm{pg} / \mathrm{m}^{3}$, with a mean concentration of $53.9 \mathrm{pg} / \mathrm{m}^{3}$. A generally declining trend of DP levels was found from the E-waste dismantling region to the peripheral areas. The median values of total DP concentrations in autumn, winter, spring and summer were $52.2,28.8,39.7$ and $30.1 \mathrm{pg} / \mathrm{m}^{3}$, respectively. The seasonal variations of DP concentrations were mainly associated with the intensity of E-waste dismantling activities and meteorological conditions. The mean value of anti-DP fractional abundance $\left(f_{\text {anti }}\right)$ was $0.74 \pm 0.08$, which was consistent with those in the commercial DP products. This study confirmed a significant emission source related to the distribution of atmospheric DP in the E-waste dismantling area and supplied information for the seasonal variation of DP in the atmosphere.
\end{abstract}

Dechlorane Plus, air, E-waste dismantling, seasonal variation

Citation: $\quad$ Sun H, Li Y, Wang P, Zheng S, Matsiko J, Wang D, Zhang W, Hao Y, Zhang Q, Jiang G. Atmospheric levels and distribution of Dechlorane Plus in an E-waste dismantling region of East China. Sci China Chem, 2017, 60: 305-310, doi: 10.1007/s11426-016-0261-6

\section{Introduction}

Dechlorane Plus (DP; molecular formula: $\mathrm{C}_{18} \mathrm{H}_{12} \mathrm{Cl}_{12}$; two stereo isomers: syn-DP and anti-DP) is a chlorinated flame retardant that is added into polymer materials to enhance their flame retardant properties. Due to the advantages of less discoloration and non-blooming, DP has been widely applied to electronic equipment, textile industry and plastic decoration materials [1]. As a substitute product of Dechlorane (Mirex), DP was once produced by Hooker Chemical (now known as OxyChem) in the 1970s. Now two major

*Corresponding author (email: qhzhang@rcees.ac.cn)
DP manufacturers are located in Niagara Falls, New York, USA [2] and in Huai' an, Jiangsu Province, China [3], respectively. Over the past decades, the volume of DP production and consumption has increased with years. The annual production of DP approximately reached 10 million pounds [4].

In 2006, Hoh et al. [2] first identified DP in ambient air, fish, and sediment samples from the Great Lakes region nearby a DP manufactory. Thereafter DP has been known as a ubiquitous contaminant and detected in various environmental and biological media, such as ambient air [4], water [5], sediment [1], indoor dust [6], plant [7,8], aquatic biota [9] and amphibian [10], terrestrial wildlife $[11,12]$, even in human serum [13] and breast milk [14]. DP 
has attracted great interest due to its similar properties (e.g., environmental persistence, bioaccumulation $[9,15,16]$, long-distance transportation [5]) to persistent organic pollutants (POPs), which may pose a potential risk to human health.

As one of long-distance transportation intermediaries, atmosphere prominently dominates in transporting DP from sources to remote areas. In recent years, the detections of DP in air samples have increased on a global scale. The DP atmospheric concentrations have been reported in the North American Great Lakes region [17,18], urban and rural sites in Asian countries including Japan [19], Korea [20], China [4] and Pakistan [21], the remote locations in the Arctic and sub-Arctic regions [22,23], as well as the marine atmosphere from Arctic to Antarctica [5,24]. During the past decade, air pollution has raised concerns in China [25,26]. The first study reported DP atmospheric concentrations in 97 urban and rural sites covering the most domestic provinces in 2008 [4]. Subsequently, some studies have investigated DP levels in the atmosphere of several large cities (Beijing [20], Shanghai [27], Harbin [28], Dalian [29], etc.), the areas surrounding DP manufacturing plants [3,30], electronic-waste (E-waste) dismantling site (Qingyuan) [31], and remote location in Tibetan Plateau [32].

E-waste dismantling region attracted great attention due to the serious environmental hazard related to E-waste dismantling activities. Many studies have observed high POPs concentrations in the environmental and biological samples from the E-waste recycling regions [33,34]. As an additive flame retardant, DP is easily released into environment during the production, use and disposal processes of DP-containing products. Moreover, the recycling process of E-waste may also lead to the release of DP into the surrounding environment, which was identified as a major emission source of DP [35]. Taizhou is one of the major E-waste dismantling regions in East China which started E-waste dismantling activities in the late 1970s. The E-waste dismantling industry employs around forty thousand people, and the annual dismantling capacity has exceeded 2.2 million metric tons [36]. In our previous study, high DP levels were measured in earthworm and agricultural soil samples collected from the E-waste recycling region in Taizhou and the concentrations in most soil samples were higher than those reported in urban areas of China [37]. However, the studies on the atmospheric DP levels in Taizhou and its spatial-temporal distributions were scarce.

In this study, we collected air samples at various locations of E-waste dismantling region in four seasons to investigate the seasonal variation of DP concentrations between the E-waste dismantling sites and peripheral sites. The potential influences on DP distribution were also discussed involving the weather and geographical conditions, as well as the E-waste dismantling activity.

\section{Experimental}

\subsection{Materials}

The reagents, dichloromethane (DCM), $n$-hexane, and acetone were pesticide grade and purchased from J. T. Baker (USA). Nonane was of chromatographic grade and purchased from Sigma-Aldrich (USA). Silica gel 60 (70-230 mesh) was supplied from Merck (Darmstadt, Germany) and baked at $550{ }^{\circ} \mathrm{C}$ for $12 \mathrm{~h}$ to activate it. Sulfuric acid and sodium hydroxide were analytically pure and obtained from Beijing Chemical Factory (China) to prepare acid silica gel $(30 \%, w / w)$ and basic silica gel $(1.2 \%, w / w)$ from activated silica gel. Anhydrous sodium sulfate was also obtained from Beijing Chemical Factory (China) and baked at $660{ }^{\circ} \mathrm{C}$ for $6 \mathrm{~h}$ before use. Carbon (Carbopak C) and Celite (545 coarse) were from Supelco (USA) and baked at $130{ }^{\circ} \mathrm{C}$ for $6 \mathrm{~h}$ after mixing $(18 \%, w / w)$. The standard solutions of syn-DP, anti- DP, ${ }^{13} \mathrm{C}_{12}-\mathrm{PCB}-138$ (injection standard) and ${ }^{13} \mathrm{C}_{12}$-PCB- 209 (surrogate standard) were purchased from Wellington Laboratories (Canada).

\subsection{Sample collection}

Passive air samplers (PASs) with polyurethane foam (PUF) disks deployed in the present study have been described previously $[38,39]$. In brief, a PUF disk was housed inside a stainless steel chamber consisting of a pole and two domes with different external diameters. The PASs were placed under the eaves, roped to trees or poles $(1.5 \mathrm{~m}$ above the ground). Air flowed into the chamber through the gap between two domes and several holes in the surface of the bottom dome. The contaminants and fine/ultrafine particles in the air were adsorbed on the surface of PUF disks. The effective concentrations of passive air samples were calculated by equivalent air volumes (effective sampling ratex sampling time) which were related to the properties of the analytes, sampling days and planar surface area of PUF disks. The PUF disks in this study are $14 \mathrm{~cm}$ in diameter and $1.35 \mathrm{~cm}$ thick, with the planar surface area of $365 \mathrm{~cm}^{2}$. According to the previous studies [3], the effective sampling rate for DP was set as $3.5 \mathrm{~m}^{3}$ per day.

The PASs were deployed in seven sites to collect air samples every three months (approximately $90 \mathrm{~d}$ for collecting each air sample) between September 2009 and August 2010. The sampling period covered four distinct seasons: autumn (from September to November), winter (from December to February of the next year), spring (from March to May) and summer (from June to August). Seven sampling sites were clustered within a $15 \mathrm{~km}$ radius of the E-waste dismantling center, and situated in two regions: E-waste recycling region $(\mathrm{S} 1-\mathrm{S} 4)$ and peripheral region (S5-S7) (Figure 1). Site 1 (S1), S2, S3 and S4 were located around the E-waste recycling plant; S5 was seated in the adjacent urban center; S6 and S7 were rural sites which 
situated in the south and east direction of recycling center, respectively.

Before sampling, PUF disks were extracted twice by the accelerated solvent extraction device (Dionex ASE 300, USA) with acetone and DCM/ $n$-hexane $(1: 1, v / v)$ as solvents at $100{ }^{\circ} \mathrm{C}, 1500 \mathrm{psi}$ and two cycles to remove impurities. After sample collection, PUF disks were wrapped by aluminum foil and sealed in package, then transported to the laboratory and stored in refrigerator at $-20{ }^{\circ} \mathrm{C}$ awaiting further analysis.

\subsection{Extraction and purification}

The extraction and purification procedures followed our previous studies $[3,40]$ with a minor modification. Briefly, PUF samples were extracted using Dionex ASE 300 with DCM: $n$-hexane $(1: 1, v / v)$ at $100{ }^{\circ} \mathrm{C}, 1500$ psi and two cycles. Prior to extraction, $10 \mu \mathrm{L}{ }^{13} \mathrm{C}_{12}$-PCB-209 $(100 \mathrm{pg} / \mu \mathrm{L})$ was spiked as the internal standard. The extract was concentrated to $2 \mathrm{~mL}$ by vacuum rotary evaporation and purified by multilayer silica gel column (from bottom to top: $1 \mathrm{~g}$ activated silica gel, $4 \mathrm{~g}$ basic silica gel, $1 \mathrm{~g}$ activated silica gel, $8 \mathrm{~g}$ of acidic silica gel, $2 \mathrm{~g}$ activated silica gel and $4 \mathrm{~g}$ anhydrous sodium sulfate). The column was pre-rinsed with $80 \mathrm{~mL} n$-hexane, and then rinsed with $100 \mathrm{~mL} n$-hexane after sample loading. The eluent was concentrated to $2 \mathrm{~mL}$ and further purified by activated carbon column (1.5 $\mathrm{g}$ activated carbon mixture at the bottom and $4 \mathrm{~g}$ anhydrous sodium sulfate at the top). The column was pre-rinsed with 50 $\mathrm{mL}$ toluene and $20 \mathrm{~mL} n$-hexane in turn, and finally eluted with $50 \mathrm{~mL} n$-hexane. The final eluent was concentrated to $1 \mathrm{~mL}$ and transferred into a vial containing $20 \mu \mathrm{L}$ nonane. The content in the vial was further evaporated to approximately $20 \mu \mathrm{L}$ under a gentle stream of nitrogen and later

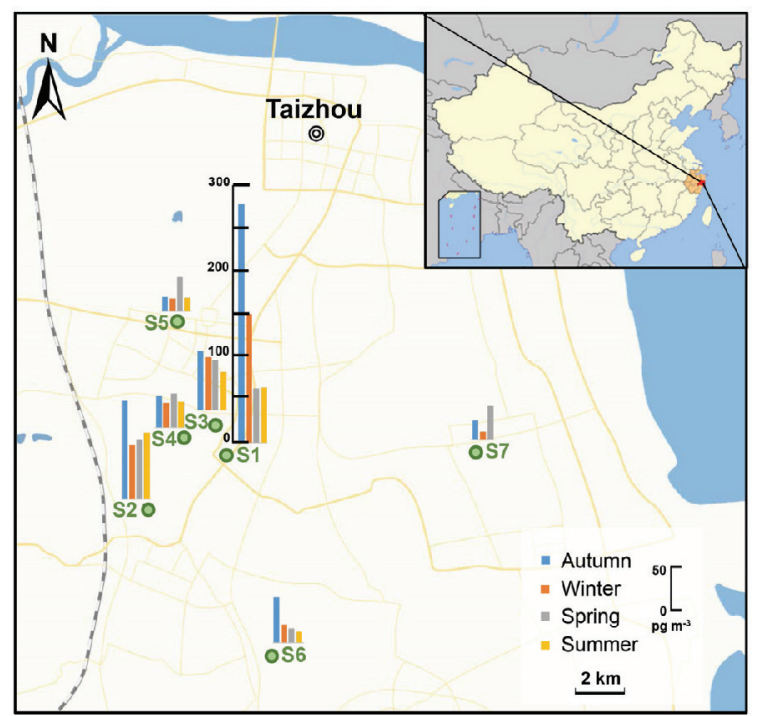

Figure 1 The sampling sites and seasonal distribution of atmospheric DP concentrations (color online). spiked with $10 \mu \mathrm{L}{ }^{13} \mathrm{C}_{12}$-PCB-138 (100 pg/ $\left.\mu \mathrm{L}\right)$ as injection standard prior to instrumental analysis.

\subsection{Instrumental analysis}

The instrumental analysis of DP was performed with gas chromatography coupled with negative chemical ionization mass spectrometer (GC-NCI-MS, SHIMADZU 2010 Ultra, Japan). The GC system applied to a DB-5MS column (15 m×0.25 mm ID, film thickness of $0.1 \mu \mathrm{m}, \mathrm{J} \& \mathrm{~W}$ Scientific, USA). Detailed information about analytical parameters was provided previously [3]. A splitless mode was selected for injection. The temperatures of injection port and the transfer line were held at $285^{\circ} \mathrm{C}$. The oven temperature was set at $100{ }^{\circ} \mathrm{C}$ initially for $4 \mathrm{~min}$, then ramped to $150{ }^{\circ} \mathrm{C}$ at $8{ }^{\circ} \mathrm{C} / \mathrm{min}$ and held for $4 \mathrm{~min}$, subsequently ramped to $300{ }^{\circ} \mathrm{C}$ at $12{ }^{\circ} \mathrm{C} / \mathrm{min}$ and held for $13 \mathrm{~min}$. Helium was used as the carrier gas with the column flow rate of $1 \mathrm{~mL} / \mathrm{min}$. The MS source temperature was set to $200^{\circ} \mathrm{C}$. Methane was used as the moderating gas. The MS system was operated in selected ion monitoring (SIM) mode with the monitoring ions: $\mathrm{m} / \mathrm{z} 653.8$ and 651.8 (syn- and anti-DP), $\mathrm{m} / \mathrm{z} 507.9$ and $509.9\left({ }^{13} \mathrm{C}_{12}\right.$-PCB-209), $\mathrm{m} / \mathrm{z}, 369.7$ and $371.7\left({ }^{13} \mathrm{C}_{12}\right.$-PCB138).

\subsection{Quality assurance and quality control (QA/QC)}

The limits of detection (LOD) for sample analysis of synand anti-DP (mean \pm standard deviation) were $0.21 \pm 0.12$ and $0.32 \pm 0.13 \mathrm{pg} / \mathrm{m}^{3}$, respectively. The recoveries of ${ }^{13} \mathrm{C}_{12^{-}}$ PCB-209 were $96.4 \% \pm 16.2 \%$ for all the samples. Four procedural blanks were paralleled along with every batch of the seven samples during experiment process for quality control. In the procedural blanks, the two isomers of DP were detected at $<5 \%$ of the levels determined in all samples except for one sample (S7 in summer) in which the concentration was extremely low and the blanks reached up to around $20 \%$ of that. The value of S7 (summer) was therefore not presented here.

\section{Results and discussion}

\subsection{Overall concentrations of DP}

In the present study, the concentrations of $\Sigma \mathrm{DP}$ (sum of synand anti-DP) ranged from not detected to $277 \mathrm{pg} / \mathrm{m}^{3}$ with median and algebraic mean values of 39.6 and $53.9 \mathrm{pg} / \mathrm{m}^{3}$. The DP levels determined in Taizhou were obviously higher than the air samples collected by PASs from urban $\left(15.6 \pm 15.1 \mathrm{pg} / \mathrm{m}^{3}\right)$ and rural $\left(3.5 \pm 5.6 \mathrm{pg} / \mathrm{m}^{3}\right)$ sites across China. In the past few years, high-volume air samplers (HVASs) were used to measure the DP atmospheric concentrations as well. The DP levels in air determined close to the Chinese DP manufacturing plant were 7737-26734 and 
$3332 \mathrm{pg} / \mathrm{m}^{3}[3,30]$. Meanwhile, the atmospheric concentrations of DP were reported in several Chinese large cities with dense population and developed industry, such as Beijing $\left(1.98 \pm 3.90 \mathrm{pg} / \mathrm{m}^{3}\right)$ [20], Shanghai $\left(5.48 \pm 1.28 \mathrm{pg} / \mathrm{m}^{3}\right)$ [27], Harbin $\left(0.35 \pm 0.21 \mathrm{pg} / \mathrm{m}^{3}\right)$ [28] and Dalian $(3 \pm 6$ $\mathrm{pg} / \mathrm{m}^{3}$ ) [29]. Although different sampling techniques (passive and active air samplers) may lead to deviation in the measured concentrations, field-based calibration studies have showed the comparability of passive and active samplers for measuring particle-associated chemicals in air [41]. The DP levels determined in Taizhou were significantly lower than DP manufacturing plant surrounding areas but higher than urban average levels. The concentrations of total DP and the anti-isomer fractional abundance $\left(f_{\text {anti }}\right)$ in the atmosphere from different areas are summarized in Table S1 (Supporting Information online). The atmospheric concentrations of DP in Taizhou were higher than most reported regions in Asia, Europe and North America. The relatively high atmospheric DP levels suggested that some DP emission sources occurred in the E-waste recycling area.

\subsection{Spatial distribution}

Among the seven sampling sites, the maximum annual $\Sigma \mathrm{DP}$ concentrations were measured in S1 adjacent to an E-waste recycling plant. The concentrations in E-waste region (S1-S4) ranged from $28.8-277 \mathrm{pg} / \mathrm{m}^{3}$ with median and algebraic mean values of 63.1 and $77.7 \mathrm{pg} / \mathrm{m}^{3}$. Meanwhile, the lower concentrations were measured in the urban (S5) and rural (S6, S7) sites (not detected-52.2 $\mathrm{pg} / \mathrm{m}^{3}$ with the median and algebraic mean values of 16.3 and $22.2 \mathrm{pg} / \mathrm{m}^{3}$ ) which were located several miles away from the E-waste recycling center. The annual mean concentration of E-waste region was approximately 4 times greater than the peripheral regions (S5-S7). The DP concentrations showed an obviously declining trend with the increasing distance from the E-waste recycling plant. This result indicated that local E-waste recycling activity was probably the primary DP emission source in study area, which adhered to our previous summarization about DP emission sources [35]. The similar result was also found in the North American Great Lakes region where the higher atmospheric DP concentrations were observed in a rural site (Sturgeon Point, NY, USA) located near the DP manufacturing facility and the concentrations of doubling distance from DP plant decreased by about $30 \%$ [18].

The atmospheric concentrations in the E-waste dismantling sites (S1-S4) were obviously lower than those from Qingyuan (13.1-1794 pg/m ${ }^{3}$, an average of $363 \mathrm{pg} / \mathrm{m}^{3}$ ) [31], another E-waste site in South China. Moreover, the similar results were obtained for some other Halogenated flame retardants (HFRs). The levels of several HFRs including polybrominated diphenyl ethers (PBDEs), hexachlorobenzene (HBB) and pentabromoethylbenzene (PBEB) detected in Taizhou were much lower than those reported in Qing- yuan [34]. Since the past decade, some measures have been taken by Chinese government in Taizhou to regulate informal E-waste recycling activities. The lower atmospheric levels of flame retardants in Taizhou may be caused by the increasingly stringent regulations on E-wastes as well as recycling methods.

\subsection{Seasonal variation}

The seasonal distribution of total DP during the sampling period (September 2009 to August 2010) is shown in Figure 1 . The median values (range) of $\Sigma \mathrm{DP}$ concentrations in autumn, winter, spring and summer were $52.2 \mathrm{pg} / \mathrm{m}^{3}$ $\left(16.1-277 \mathrm{pg} / \mathrm{m}^{3}\right), 28.8 \mathrm{pg} / \mathrm{m}^{3}\left(9.3-149 \mathrm{pg} / \mathrm{m}^{3}\right), 39.7 \mathrm{pg} / \mathrm{m}^{3}$ $\left(16.5-69.3 \mathrm{pg} / \mathrm{m}^{3}\right.$ ) and $30.1 \mathrm{pg} / \mathrm{m}^{3}$ (not detected-77.7 $\mathrm{pg} / \mathrm{m}^{3}$ ), respectively. The maximum atmospheric DP level was observed in autumn, followed by spring and summer, whereas the DP overall concentration in winter was the minimum. Moreover, the highest concentrations in the E-waste recycling region (S1-S4) and a rural site (S6) were detected in autumn, while the highest level in the other peripheral sites (S5 and S7) was in spring.

The intensity of local dismantling activities and variable meteorological conditions were probably the main factors on the seasonal variation in Taizhou. According to previous study, the atmospheric DP concentrations at E-waste sites were highly dependent upon the strength of the emission source [31]. The historical data of the amount of dismantled E-waste in Taizhou showed that more E-wastes were recycled from April to June and October to December [42]. The higher DP concentrations in autumn and spring were consistent with the larger dismantled E-wastes in these seasons.

Due to the high octanol-air partition coefficient $\left(\log K_{\mathrm{OA}}=\right.$ 12.26 [43]), DP is a particle-associated chemical and mostly detected in particle phase [3]. However, the PASs used in this study could mainly collect gas phase samples with rarely fine/ultrafine particles absorbed by PUF disks [44]. As the particle number concentrations and size distributions in air are affected by the meteorological conditions, the different weather conditions (precipitation, particulate pollution and seasonal winds) influenced the atmospheric DP concentrations to some degree. Since Taizhou is located on the eastern coast of China, it has a subtropical monsoon climate with four distinctive seasons. Northerly winds prevail in winter and southerly winds reign in summer. The mean annual temperatures were between 17.2 to $18{ }^{\circ} \mathrm{C}$ with the highest temperature in July and the lowest in January. The annual rainfalls ranged from 1744 to $2483 \mathrm{~mm}$ and more precipitations were observed in June and July $[45,46]$. According to the monitoring data, the heavy particulate pollution generally occurred from April to June and October to December $[47,48]$. Less precipitation, heavy particulate pollution as well as frequent E-waste dismantling activities in autumn resulted in the highest DP concentration in that season. As the wind direction in Taizhou changes with the 
seasons, the seasonal wind affected the DP levels of peripheral sites to varying degrees. S5 and S6 are situated in the downwind area at spring and autumn, where the highest concentrations were observed in spring and autumn, respectively. Since S7 was not present in the main wind direction area, the higher concentrations were measured in both spring and autumn which were mainly influenced by the frequent E-waste recycling activities in these seasons.

The seasonal variations of atmospheric DP concentrations in Taizhou were different from another E-waste recycling region. Chen et al. [31] investigated the monthly variabilities of DP in Qingyuan and detected the relatively high DP levels from January to April in the E-waste site and in February and March at the reference site. The different seasonal pattern of DP in the air between two E-waste recycling regions was probably caused by local dismantling activities. The higher DP concentrations in Qingyuan during January to April depended on the frequent dismantling activities in that period. Additionally, the different air-sampling methods and meteorological parameters were other factors influencing these levels.

Although the atmospheric DP concentrations in Taizhou were scarce, seasonal variations of some other HFRs were measured in previous studies. The total PBDEs levels in the atmosphere at E-waste recycling region were strikingly higher than those at the reference site and the winter levels of PBDEs was about 3 times of that in summer, which should be mainly due to the different meteorological conditions in two seasons [49]. Nevertheless, in a subsequent research, Zhang et al. [34] reported that the higher atmospheric concentrations of PBDEs, HBB and PBEB observed in summer and the various PBDEs congener profiles in summer and winter may reflect the different emission mechanisms in two seasons. Despite the different results, the influence of weather conditions and emission source were speculated as the main factors, which is in correspondence with our study. However, the relationships among DP concentrations, meteorological conditions (temperature, precipitation and wind speed) and intensity of dismantling activities require further investigation.

\subsection{DP isomer ratios}

The fractional abundance $\left(f_{\text {anti }}\right)$ value is used to represent the composition of DP isomers, which is defined as follow [13]:

$$
f_{\text {anti }}=[\text { anti-DP }] /([\text { anti-DP }]+[\text { syn-DP }])
$$

The $f_{\text {anti }}$ values of technical DP products determined in previous studies were not constant. The values of the products from OxyChem were ranged from 0.64 to 0.80 [2,9,50], whereas the values from the Chinese DP manufacture plant were $0.70 \pm 0.003$ [15] and $0.68 \pm 0.01$ [3]. During the long-range atmospheric transport from the pollution source to the remote area, the sun-irradiation and biological effects will change the two stereo isomers proportions to some ex- tent. The apparent decline of $f_{\text {anti }}$ values $(0.36 \pm 0.12)$ [24] were observed in the marine atmosphere, which could reflect the influence of atmospheric transport on DP isomer composition. Therefore, the proportion of a DP isomer can reflect the presence of local sources.

In this study, the annual $f_{\text {anti }}$ value (mean \pm standard deviation) was $0.74 \pm 0.08$ (Figure 2$)$. The $f_{\text {anti }}$ values in E-waste recycling region $(0.75 \pm 0.06)$ were higher than the peripheral region $(0.73 \pm 0.10)$, but there was no significant difference observed in two regions (Mann-Whitney $\mathrm{U}$ test, $p=$ 0.33 ). In our previous study, the $f_{\text {anti }}$ values in soil samples collected from various farmland locations in Taizhou ranged from 0.57 to 0.80 , with a mean value of 0.71 [37]. The $f_{\text {anti }}$ values in the air were in agreement with the soil samples collected at the same period. The values of $f_{\text {anti }}$ in Taizhou were comparable to those obtained in another E-waste site $(0.726 \pm 0.037)$ [31] and were closed to the commercial products. The values were higher than the mean value of many Chinese urban $(0.67 \pm 0.10)$ and rural $(0.66 \pm 0.11)$ areas [4]. The higher $f_{\text {anti }}$ values in E-waste recycling region were coincident with the presence of local emission source. Furthermore, the $f_{\text {anti }}$ values of autumn, winter, spring and summer were $0.78 \pm 0.05,0.70 \pm 0.07$, $0.71 \pm 0.09$ and $0.79 \pm 0.05$, respectively. The value of $f_{\text {anti }}$ in autumn and summer were higher than spring and winter, but the differences among four seasons were not significant (one-way ANOVA on ranks, $p=0.055$ ). This result suggested that both DP isomers were stable in the atmosphere and basically invariable with weather conditions.

\section{Conclusions}

In this study, atmospheric DP concentrations were measured in an E-waste dismantling region in East China. Relatively high DP levels were found in this study which suggested that E-waste dismantling activity was the major DP emission source in the local area. DP concentrations in the air showed a decreasing trend with the increasing distance from the E-waste dismantling plant and the average DP

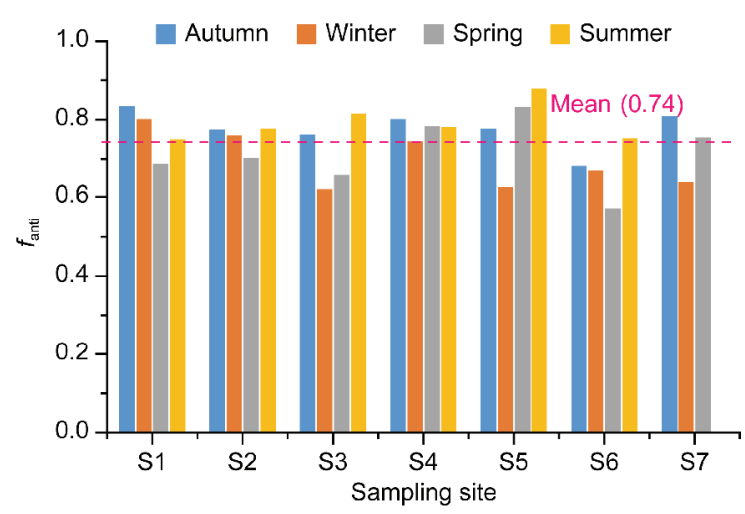

Figure 2 The $f_{\text {anti }}$ value of air samples (color online). 
concentrations near the E-waste site were several times higher than those in the peripheral regions. Moreover, the seasonal variation was also observed in the study areas. The higher DP levels were measured in autumn around E-waste sites while in spring and autumn at the peripheral regions. The meteorological conditions and the intensity of dismantling activities were probably the primary reasons for the seasonal variation of DP levels. The $f_{\text {anti }}$ values were similar to DP commercial products, indicating there was no stereo selectivity of atmospheric DP occurred in this E-waste recycling area.

Acknowledgments This work was supported by the National Natural Science Foundation of China $(21477156,21277165)$, the National Basic Research Program of China (2015CB453101) and the Strategic Priority Research Program of the Chinese Academy of Sciences (XDB14010100).

Conflict of interest The authors declare that they have no conflict of interest.

Supporting information The supporting information is available online at chem.scichina.com and link.springer.com/journal/11426. The supporting materials are published as submitted, without typesetting or editing. The responsibility for scientific accuracy and content remains entirely with the authors.

1 Qiu XH, Marvin CH, Hites RA. Environ Sci Technol, 2007, 41: 6014-6019

2 Hoh E, Zhu LY, Hites RA. Environ Sci Technol, 2006, 40: 1184-1189

3 Zhang QH, Zhu CF, Zhang HD, Wang P, Li YM, Ren DW, Jiang GB. Sci Bull, 2015, 60: 792-797

4 Ren NQ, Sverko E, Li YF, Zhang Z, Harner T, Wang DG, Wan XN, McCarry BE. Environ Sci Technol, 2008, 42: 6476-6480

5 Moeller A, Xie ZY, Sturm R, Ebinghaus R. Environ Sci Technol, 2010, 44: 8977-8982

6 Zhu JP, Feng YL, Shoeib M. Environ Sci Technol, 2007, 41: 7694-7698

7 Qiu XH, Hites RA. Environ Sci Technol, 2008, 42: 31-36

8 Na GS, Wei W, Zhou SY, Gao H, Ma XD, Qiu LN, Ge LK, Bao CG, Yao ZW. J Environ Sci, 2015, 28: 8-13

9 Tomy GT, Pleskach K, Ismail N, Whittle DM, Helm PA, Sverko E, Zaruk D, Marvin CH. Environ Sci Technol, 2007, 41: 2249-2254

10 Li L, Wang WY, Lv QX, Ben YJ, Li XH. J Environ Sci, 2014, 26: 636-642

11 Gauthier LT, Hebert CE, Weseloh DVC, Letcher RJ. Environ Sci Technol, 2007, 41: 4561-4567

12 Guerra P, Fernie K, Jimenez B, Pacepavicius G, Shen L, Reiner E, Eljarrat E, Barcelo D, Alaee M. Environ Sci Technol, 2011, 45: 1284-1290

13 Ren GF, Yu ZQ, Ma ST, Li HR, Peng P, Sheng GY, Fu JM. Environ Sci Technol, 2009, 43: 9453-9457

14 Ben YJ, Li XH, Yang YL, Li L, Di JP, Wang WY, Zhou RF, Xiao K, Zheng MY, Tian Y, Xu XB. Environ Pollut, 2013, 173: 176-181

15 Wu JP, Zhang Y, Luo XJ, Wang J, Chen SJ, Guan YT, Mai BX. Environ Sci Technol, 2010, 44: 606-611

16 Tomy GT, Thomas CR, Zidane TM, Murison KE, Pleskach K, Hare J, Arsenault G, Marvin CH, Sverko E. Environ Sci Technol, 2008, 42: 5562-5567

17 Venier M, Hites RA. Environ Sci Technol, 2008, 42: 4745-4751

18 Salamova A, Hites RA. Environ Sci Technol, 2011, 45: 9924-9930

19 Kakimoto K, Nagayoshi H, Takagi S, Akutsu K, Konishi Y, Kaji- mura K, Hayakawa K, Toriba A. Ecotox Environ Safe, 2014, 99: 69-73

20 Kakimoto K, Nagayoshi H, Akutsu K, Konishi Y, Kajimura K, Hayakawa K, Toriba A. Environ Sci Pollut Res, 2015, 22: 14600-14605

21 Syed JH, Malik RN, Li J, Wang Y, Xu Y, Zhang G, Jones KC. Chemosphere, 2013, 93: 1646-1653

22 Xiao H, Shen L, Su YS, Barresi E, DeJong M, Hung HL, Lei YD, Wania F, Reiner EJ, Sverko E, Kang SC. Environ Pollut, 2012, 161: 154-161

23 Salamova A, Hermanson MH, Hites RA. Environ Sci Technol, 2014, 48: 6133-6140

24 Moeller A, Xie ZY, Cai MH, Zhong GC, Huang P, Cai MG, Sturm R, He JF, Ebinghaus R. Environ Sci Technol, 2011, 45: 6793-6799

25 Wang S, Li GG, Gong ZY, Du L, Zhou QT, Meng XY, Xie SY, Zhou L. Sci China Chem, 2015, 58: 1435-1443

26 Chen HS, Li J, Ge BZ, Yang WY, Wang ZF, Huang S, Wang YL, Yan PZ, Li JJ, Zhu LL. Sci China Chem, 2015, 58: 1403-1415

27 Yu ZQ, Liao RE, Li HR, Mo LG, Zeng XY, Sheng GY, Fu JM. Environ Pollut, 2011, 159: 2982-2988

28 Ma WL, Liu LY, Hong Q, Sun DZ, Shen JM, Wang DG, Li YF. Environ Int, 2011, 37: 66-70

29 Yang M, Jia HL, Ma WL, Qi H, Cui S, Li YF. Atmos Environ, 2012, 55: 73-79

30 Wang DG, Yang M, Qi H, Sverko E, Ma WL, Li YF, Alaee M, Reiner EJ, Shen L. Environ Sci Technol, 2010, 44: 6608-6613

31 Chen SJ, Tian M, Wang J, Shi T, Luo Y, Luo XJ, Mai BX. Environ Pollut, 2011, 159: 1290-1296

32 Yu Y, Hung H, Alexandrou N, Roach P, Nordin K. Environ Sci Technol, 2015, 49: 8623-8630

33 Zhu CF, Wang P, Li YM, Chen ZJ, Li WJ, Ssebugere P, Zhang QH, Jiang GB. Environ Sci Process Impacts, 2015, 17: 693-699

34 Zhang T, Huang YR, Chen SJ, Liu AM, Xu PJ, Li N, Qi L, Ren Y, Zhou ZG, Mai BX. J Environ Monit, 2012, 14: 3156-3163

35 Wang P, Zhang QH, Zhang HD, Wang T, Sun HZ, Zheng SC, Li YM, Liang Y, Jiang GB. Environ Int, 2016, 88: 206-220

36 Tang W, Cheng JP, Zhao WC, Wang WH. J Environ Sci, 2015, 34: $107-132$

37 Xiao K, Wang P, Zhang HD, Shang HT, Li YM, Li XH, Ren DW, Chen WH, Zhang QH. Environ Geochem Health, 2013, 35: 625-631

38 Pozo K, Harner T, Shoeib M, Urrutia R, Barra R, Parra O, Focardi S. Environ Sci Technol, 2004, 38: 6529-6537

39 Harner T, Shoeib M, Diamond M, Stern G, Rosenberg B. Environ Sci Technol, 2004, 38: 4474-4483

40 Zhang HD, Wang P, Li YM, Shang HT, Wang YW, Wang T, Zhang QH, Jiang GB. Environ Sci Technol, 2013, 47: 10567-10573

41 Markovic MZ, Prokop S, Staebler RM, Liggio J, Harner T. Atmos Environ, 2015, 112: 289-293

42 http://lqhb.luqiao.gov.cn/YGGC/ArticleList.aspx?CategoryID=2047 \&CurrentPageIndex $=1$, accessed on 2016-07-29

43 Sverko E, Tomy GT, Reiner EJ, Li YF, McCarry BE, Arnot JA, Law RJ, Hites RA. Environ Sci Technol, 2011, 45: 5088-5098

44 Klanova J, Eupr P, Kohoutek J, Harner T. Environ Sci Technol, 2008, 42: 550-555

45 http://www.zjtz.gov.cn/art/2014/5/14/art_3327_90277.html, accessed on 2016-07-29

46 http://www.zjtz.gov.cn/art/2014/5/14/art_3353_90110.html, accessed on 2016-07-29

47 http://www.zjtz.gov.cn/art/2014/4/18/art_3374_90192.html, accessed on 2016-07-29

48 http://www.zjtz.gov.cn/art/2014/4/18/art_3343_90354.html, accessed on 2016-07-29

49 Han W, Feng J, Gu Z, Chen D, Wu M, Fu J. Bull Environ Contam Toxicol, 2009, 83: 783-788

50 Sverko E, Tomy GT, Marvin CH, Zaruk D, Reiner E, Helm PA, Hill B, McCarry BE. Environ Sci Technol, 2008, 42: 361-366 